\title{
Unequal Protection Revisited: Planning for Environmental Justice, Hazard Vulnerability, and Critical Infrastructure in Communities of Color
}

\author{
Marccus D. Hendricks and Shannon Van Zandt
}

\begin{abstract}
Existing environmental justice (EJ) and hazard vulnerability literatures inadequately address key texts and topics related to critical physical infrastructure, including stormwater, green space, sewerage, energy, and roads, among other systems. This scoping review demonstrates how fundamental principles of EJ can bolster and compliment those of social vulnerability (SV) with a focus on stormwater systems and flood risks. The discussion and conceptual framework provide in-depth insight to how neighborhoods are not inherently vulnerable, but occupy built environments that are systematically sequestered, neglected, and underserved. Social processes and larger planning and development patterns shaped by power and privilege create areas of both prosperity and disadvantage. These outcomes are brought about specifically by early racial zoning, segregation, legalized redlining, and ultimately the isolation of racial minorities that have led to diminished tax bases and built environments in disrepair. Thus, infrastructural robustness and resilience at the neighborhood level result directly from human decisions and social ideologies of environmental racism and classism. The associated human-built environment manifests social and physical circumstances of damage and disease mentioned in both the SV and EJ literatures. The built environment must be explored with a progressive lens that views physical infrastructure as an extension of social circumstances to gain a comprehensive and robust understanding of how low-income communities and communities of color are unequally managed and protected in both daily environmental conditions and extreme events.
\end{abstract}

Keywords: hazards, disasters, social vulnerability, infrastructure, built environment, inequality

\section{INTRODUCTION}

$\mathbf{J}$ UST OVER 25 years have passed since Dr. Robert D. Bullard wrote one of several profound anthologies on environmental racism and injustice across America, discussing everything from the development of minority neighborhoods on SuperFund sites to the disproportionate burden of petrochemical facilities in communities of color. ${ }^{1}$

Dr. Marccus D. Hendricks is an Assistant Professor at Urban Studies and Planning Program, School of Architecture, Planning and Preservation, University of Maryland, College Park, Maryland, USA.

Dr. Shannon Van Zandt is a Professor and Department Head at Landscape Architecture and Urban Planning, College of Architecture, Texas A\&M University, College Station, Texas, USA.

${ }^{1}$ Robert D. Bullard. Unequal Protection: Environmental Justice and Communities of Color. (San Francisco: Sierra Club Books, 1994).
As one of the most recognized scholars in the environmental justice (EJ) movement, Bullard's collection of work has drawn associations between communities of color and environmental burden through case studies from around the country, setting the stage for three decades of EJ scholarship.

In light of growing inequalities evident in outcomes related to urban resilience, climate change, natural hazards, and decaying critical infrastructure, the EJ agenda must expand its horizon to include this new suite of environmental issues. Historically, the EJ agenda has primarily focused on issues such as the siting of toxic and waste treatment facilities. Yet, disparate impacts from both climate and technological disasters demonstrate the need to consider both traditional problems and emerging issues of critical infrastructure for public safety that mediates experiences of risks and resilience. 
Latent environmental and built environment issues, such as inadequate or improperly maintained roads, sidewalks, and stormwater management systems, are not as noticeable as chemical facilities or landfills because they are built norms for communities of color and most often are due to institutional racism that these communities live with every day. Often these issues do not receive compliance violations or disaster declarations, but nonetheless pose adverse effects at various scales. Specifically, this article conceptualizes the role of infrastructure (such as stormwater and sewers) as a mechanism that transmits and furthers environmental injustice and disparate impacts across population groups both every day and during environmental extremes.

To place infrastructure within this discussion of inequality, we integrate the literature on social vulnerability to disasters (SV) with that of EJ. The social vulnerability literature is an extension of the traditional hazard vulnerability literature that narrowly focused on risk and physical vulnerability in terms of geographic location and proximity to a hazard.

Social vulnerability is an improvement on that longstanding literature in its focus on disparate exposure, impact, damage, and recovery outcomes from natural hazards for certain population groups. More specifically, the SV approach describes how social stratification based on race, income, disability, gender, age, nationality, among others, contributes to differential risks and impacts from disasters. ${ }^{2,3,4}$ Social vulnerability scholars also question the built environment and spaces that these marginalized groups occupy and how these physical features contribute to disparate impacts. $5,6,7,8,9$

The EJ literature has focused on similar disparities but among man-made environmental hazards and toxic

${ }^{2}$ Ben Wisner, Piers Blaikie, Terry Cannon, and Ian Davis. At Risk: Natural Hazards, People's Vulnerability and Disasters. (New York, NY: Routledge, 2004).

${ }^{3}$ Deborah S.K. Thomas, Brenda D. Phillips, William E. Lovekamp, and Alice Fothergill (eds). Social Vulnerability to Disasters. (Boca Raton, FL: CRC Press, 2013).

${ }^{4}$ Barry E. Flanagan, Edward W. Gregory, Elaine J. Hallisey, Janet L. Heitgerd, and Brian Lewis. "A Social Vulnerability Index for Disaster Management." Journal of Homeland Security and Emergency Management 8 (2011): 3.

${ }^{5}$ Wesley E. Highfield, Walter Gillis Peacock, and Shannon Van Zandt. "Mitigation Planning Why Hazard Exposure, Structural Vulnerability, and Social Vulnerability Matter." Journal of Planning Education and Research 34 (2014): 287-300.

${ }^{6}$ Shannon Van Zandt, Walter Gillis Peacock, Dustin W. Henry, Himanshu Grover, Wesley E. Highfield, and Samuel D. Brody. "Mapping Social Vulnerability to Enhance Housing and Neighborhood Resilience." Housing Policy Debate 22 (2012): 29-55.

Sammy Zahran, Samuel D. Brody, Walter Gillis Peacock, Arnold Vedlitz, and Himanshu Grover. "Social Vulnerability and the Natural and Built Environment: A Model of Flood Casualties in Texas." Disasters 32 (2008): 537-560.

${ }^{8}$ Diana Mitsova, Ann-Margaret Esnard, Alka Sapat, and Betty S. Lai. "Socioeconomic Vulnerability and Electric Power Restoration Timelines in Florida: The Case of Hurricane Irma." Natural Hazards 94 (2018): 689-709.

${ }^{9}$ Susan L. Cutter, Bryan J. Boruff, and W. Lynn Shirley, W. L. "Social Vulnerability to Environmental Hazards." Social Science Quarterly 84 (2003): 242-261. facilities. This article tackles the rich opportunity to create a framework that merges these two literatures to address growing climate-related and natural hazard issues, with a focus on the role of infrastructure, public works, and capital improvement or lack thereof in producing and maintaining unequal exposure and disaster outcomes for marginalized population groups. Furthermore, this work builds on ideas that Cutter and Bolin first raised, acknowledging how EJ applied to hazards research, illuminating the value of tracing the development of urban hazardscapes, and comparing neighborhoods facing the greatest risks with those who are able to avoid them through zoning and land-use controls, housing deeds, and capital improvements, among others. ${ }^{10,11}$

The article begins with the underlying theories in EJ and SV to highlight issues that are not adequately addressed and show how fundamental principles of EJ can complement and bolster those of SV. To link the two theories to infrastructure, formal planning and development policies and patterns are discussed, including racial zoning, residential segregation, discriminatory planning, and neighborhood disinvestment, to provide insight to how social ideologies and the human-built environment has shaped circumstances for vulnerable communities of color. This background provides the foundation for the argument that critical infrastructure (i.e., physical safetynets and lifelines) and the built environment are the physical manifestation of social circumstances (e.g., race, socioeconomics, culture, education, and politics) and are complicit in generating the observed disparities across environmental and disaster outcomes.

Critical infrastructure as a mechanism of generating environmental protection or exacerbating hazards is the new nexus for environmental injustice and hazard vulnerability. Therefore, these physical issues have to be explored with a progressive lens that views built features as a continuation of social circumstances for a comprehensive and robust understanding of how low-income communities and communities of color are unequally protected from natural hazards and environmental threats.

\section{LITERATURE REVIEW}

\section{Environmental justice}

"The nation's environmental laws, regulations, and policies have not been applied fairly across all segments of the population. Some individuals, groups, and communities receive less protection than others because of their geographic location, race, and economic status.", 1 These words describe the unequal protection of communities of color and are the central premise of EJ research and activism. The EJ framework focuses primarily on revealing the underlying presumptions that influence environmental decision making and how these decisions

\footnotetext{
${ }^{10}$ Susan L. Cutter. "Race, Class and Environmental Justice." Progress in Human Geography 19 (1995): 111-122.

${ }^{18}$ Bob Bolin. "Race, Class, Ethnicity, and Disaster Vulnerability." In Handbook of Disaster Research (New York, NY: Springer, 2007), 113-129.
} 
result in disparate outcomes across population groups. It also rests on an analysis of strategies to eliminate unfair, unjust, and inequitable conditions and decisions. The EJ framework more precisely brings to surface the ethical and political questions of who gets what, why, and in what amount. $^{12}$

Environmental activism and the systematic study of environmental circumstances especially for communities of color are not new. In fact, some of the early work of W.E.B. DuBois, specifically in The Philadelphia Negro, is an example of some of the earliest of works that studied the Black community and used mixed-methods research to document the social environment that Blacks in American cities, Philadelphia precisely, inhabited during and following the reconstruction era. ${ }^{13}$ This was the first scholarly race study of urban life for Black Americans and catalyzed the trend for social surveys and case studies using both quantitative and qualitative methods to demonstrate inequities in the Black urban experience through the examination of housing, health, poverty, employment, and education, among others. DuBois' work was the first to show that Blacks in American cities were much more likely in comparison to Whites to suffer from or experience illiteracy, unemployment, unlivable wages, higher death rates, alcoholism, and unsanitary and unsafe living conditions.

However, EJ scholarship and the modern movement by the same name, by most accounts, point to the protests of 1982 in Warren County, North Carolina, as the beginning of the EJ movement. The protests began when a site (Afton) in Warren County was selected by the state to host a hazardous waste landfill to dump over 6000 truckloads of 30,000 cubic yards of polychlorinated biphenyl (PCB)-contaminated soil in what was a predominately Black, rural, and poor area. ${ }^{1,4,14,15}$ The publication of two studies surrounding this incident, one by the United States General Accounting Office (USGAO) and another by the United Church of Christ's Commission for Racial Justice, incited the movement and provided empirical evidence for the claims of environmental racism. ${ }^{4}$

Robert Bullard's Dumping in Dixie contributed to evidence for the disproportionate burden of toxic waste on communities of color and essentially earned him the title "Father of the Environmental Justice Movement." Since that time, hundreds of studies have documented unequal exposures along the lines of race, ethnicity, and

\footnotetext{
${ }^{12}$ Robert D. Bullard and John Lewis. Environmental Justice and Communities of Color. (San Francisco, CA: Sierra Club Books, 1996).

${ }^{13}$ William Edward Burghardt Du Bois. The Philadelphia Negro: A Social Study. No. 14. (Philadelphia, PA: University of Pennsylvania Press, 1899).

${ }^{14}$ Robert Bullard. Dumping in Dixie. (Boulder, CO: Westview, 1990).

${ }^{15}$ Dorceta E. Taylor. "Introduction: The Evolution of Environmental Justice Activism, Research, and Scholarship." Environmental Practice 13 (2011): 280-301.
}

class including issues related to climate change, disasters, and infrastructure. $16,17,18,19,20,21,22,23,24$

Houston, Texas, experience with 2017s Hurricane Harvey provides an instructive example for these intersections of EJ with SV to disasters. Houston is home to more than 10 oil refineries and numerous other technological hazards, many of which are located immediately adjacent to residential neighborhoods, primarily occupied by Hispanic or Black households. The unprecedented flooding experienced during the storm led to undetected or unreported exposures to contaminants, as the floodwaters inundated storage tanks as well as buffer areas meant to contain contaminated equipment. ${ }^{25,26}$ The disaster literature refers to these cascading events as "natech" disasters, where a natural hazard leads to a

\footnotetext{
${ }^{16}$ Maricarmen Hernandez, Timothy W. Collins, and Sara E. Grineski. "Immigration, Mobility, and Environmental Injustice: A Comparative Study of Hispanic People's Residential Decision-Making and Exposure to Hazardous Air Pollutants in Greater Houston, Texas." Geoforum 60, (2015): 83-94.

${ }^{17}$ Shawn M. Landry and Jayajit Chakraborty. "Street Trees and Equity: Evaluating the Spatial Distribution of an Urban Amenity." Environment and Planning A 41 (2009): 2651-2670.
}

${ }^{18}$ Sacoby M. Wilson, Roland Richard, Lesley Joseph, and Edith Williams. "Climate Change, Environmental Justice, and Vulnerability: An Exploratory Spatial Analysis." Environmental Justice 3 (2010): 13-19.

${ }^{19}$ Jennifer R. Wolch, Jason Byrne, and Joshua P. Newell. "Urban Green Space, Public Health, and Environmental Justice: The Challenge of Making Cities 'Just Green Enough'.' Landscape and Urban Planning 125 (2014): 234-244.

${ }^{20}$ Jayajit Chakraborty, Timothy W. Collins, and Sara E. Grineski. "Exploring the Environmental Justice Implications of Hurricane Harvey Flooding in Greater Houston, Texas." American Journal of Public Health 109 (2019): 244-250.

${ }^{21}$ Kristie S. Gutierrez and Catherine E. LePrevost. "Climate Justice in Rural Southeastern United States: A Review of Climate Change Impacts and Effects on Human Health." International Journal of Environmental Research and Public Health 13 (2016): 189.

${ }^{22}$ Susan L. Cutter, William D. Solecki, Nancy Bragado, JoAnn Carmin, Michail Fragkias, Matthias Ruth, and Thomas J. Wilbanks. "Ch. 11: Urban Systems, Infrastructure, and vulnerability." Climate Change Impacts in the United States: The Third National Climate Assessment 10 (2014): J0F769GR.

${ }^{23}$ Beverly Wright. "Race, Place, and the Environment in the Aftermath of Katrina." Anthropology of Work Review 32 (2011): 4-8.

${ }^{24}$ Ashley Baker, Emma Brenneman, Heejun Chang, Lauren McPhillips, and Marissa Matsler. "Spatial Analysis of Landscape and Sociodemographic Factors Associated with Green Stormwater Infrastructure Distribution in Baltimore, Maryland and Portland, Oregon." Science of the Total Environment 664 (2019): 461-473.

${ }^{25}$ Mathias J. Friedrich. "Determining Health Effects of Hazardous Materials Released During Hurricane Harvey." JAMA 318 (2017): 2283-2285.

${ }^{26}$ Ibraheem Karaye, Kahler W. Stone, Gaston A. Casillas, Galen Newman, and Jennifer A. Horney. "A Spatial Analysis of Possible Environmental Exposures in Recreational Areas Impacted by Hurricane Harvey Flooding, Harris County, Texas." Environmental Management 64 (2019): 381-390. 
technological disaster. Yet, very little attention was paid to these exposures by the national mainstream media.

This discussion of disaster impacts and vulnerability provides a bridge between traditional EJ research and disaster scholarship that focuses on social vulnerability. The hazard and disaster literature also developed a discussion of social stratification and disparate impacts from natural hazards, but this literature is mostly disconnected from the body of work on EJ. Likewise, the EJ work that explores instances of disaster and vulnerability are underdeveloped. Understanding the two together is necessary to address questions about infrastructure and planning for equitable communities across complex environmental problems of the future.

\section{Physical vulnerability}

Physical vulnerability in a natural hazards context is usually characterized by physical (e.g., environmental) conditions such as location and proximity to a hazardous threat. ${ }^{27,28,29}$ Brody et al. (2014) (p. 89) wrote, "Living adjacent to the coastline and/or areas of low elevation presents obvious threats from hazards. Thus, physical position and proximity characteristics lend themselves to increased potential negative hazard exposure impacts." 19 Several studies have tested the effects and explanatory power of physical vulnerability variables such as storm shutters, location to floodplains, building codes, and mitigation policies on predicting flood exposure, individual risk perceptions, damage amounts, flood claim data, and climate change impacts. ${ }^{19,30}$

These studies have generally found that these "physical" attributes do have some explanatory power but do not wholly account for variation the effects of disaster across population groups. Most of these issues and uncertainties can be better explained by including variables related to social vulnerability.

\section{Social vulnerability}

Social vulnerability goes beyond physical risk and takes into consideration individual and community socioeconomic characteristics, capacities, culture, education, and politics that impact the abilities to antici-

\footnotetext{
${ }^{27}$ Samuel D. Brody, Sammy Zahran, Arnold Vedlitz, and Himanshu Grover. "Examining the Relationship Between Physical Vulnerability and Public Perceptions of Global Climate Change in the United States." Environment and Behavior 40 (2008): 72-95.

${ }^{28}$ John Douglas. "Physical Vulnerability Modelling in Natural Hazard Risk Assessment." Natural Hazards and Earth System Science 7 (2007): 283-288.

${ }^{29}$ Marco Uzielli, Farrokh Nadim, Suzanne Lacasse, and Amir M. Kaynia. "A Conceptual Framework for Quantitative Estimation of Physical Vulnerability to Landslides." Engineering Geology 102 (2008): 251-256.

${ }^{30}$ Susan L. Cutter and Christopher T. Emrich. "Moral Hazard, Social Catastrophe: The Changing Face of Vulnerability Along the Hurricane Coasts." The Annals of the American Academy of Political and Social Science 604 (2006): 102-112.
}

pate, respond, cope, and recover from hazardous events. $2,3,4,31,32,33,34,35,36$ Social vulnerability is drawn from literature on social inequalities and macrosocial ideologies, such as racism, classism, and sexism, which effect various groups' likelihood of exposure and ability to resist disaster impacts, and should be named as such. ${ }^{3,5,37}$ This perspective is based on numerous studies following disasters that show even with similar physical risk, such as living in a floodplain, certain population groups are more likely to be injured or killed, have higher damage rates, and slower recovery rates.

In general, race, class, gender, and age are the most common proxy variables that allow us to estimate social vulnerability. ${ }^{3}$ But scholars use a number of different indicators of population variation to help explain social vulnerability and variance in disaster effects, including socioeconomic status, gender, race and ethnicity, age, commercial and industrial development, employment status, infrastructure and lifelines, occupation, family structure, education, population growth, medical services, social dependence, special needs populations, education, religion, social isolation, and housing tenure. ${ }^{2-6}$

The examination and discussion of the historical and cultural complexities of race and ethnicity in the disaster literature is limited, ${ }^{5}$ perhaps because of the complexities inherent in disaster research itself. There is a tendency to rely most often on surface level indicators and proxies for the more substantive issues. ${ }^{23-27}$ Earlier work done by Peacock et al. (1997) noted that disaster event marginalization is not a result of a single event or the disaster agent itself, but rather a series of obstacles built into the urban social structure that places certain neighborhoods and households at substantially higher risk. ${ }^{33}$ This notion runs parallel with implications from the EJ literature. Thus, it is imperative that we explicitly call out issues of racism and classism in the context of social vulnerability, just as it is done in environmental racism and EJ. ${ }^{5,38}$

\footnotetext{
${ }^{31}$ Betty Hearn Morrow. "Identifying and Mapping Community Vulnerability." Disasters 23 (1999): 1-18.

${ }^{32}$ Kathleen Tierney. "Social Inequality, Hazards, and Disasters." In On Risk and Disaster: Lessons from Hurricane Katrina. Ronald J. Daniels, Donald F. Kettl, and Howard Kunreuther (eds). (Philadelphia, PA: University of Pennsylvania Press, 2006), 109-128.

${ }^{33}$ Walter Gillis Peacock, Betty Hearn Morrow, and Hugh Gladwin. Hurricane Andrew: Ethnicity, Gender and the Sociology of Disasters. (New York, NY: Routledge, 1997).

${ }^{34}$ Alice Fothergill and Lori A. Peek. "Poverty and Disasters in the United States: A Review of Recent Sociological Findings." Natural Hazards 32 (2004): 89-110.

${ }^{35}$ Michel Masozera, Melissa Bailey, and Charles Kerchner. "Distribution of Impacts of Natural Disasters Across Income Groups: A Case Study of New Orleans." Ecological Economics 63 (2007): 299-306.

${ }^{36}$ Alice Fothergill. Heads Above Water: Gender, Class, and Family in the Grand Forks Flood. (Albany, NY: SUNY Press, 2012).

${ }^{37}$ Fayola Jacobs. "Black Feminism and Radical Planning: New Directions for Disaster Planning Research." Planning Theory 18 (2019): 24-39.

${ }^{38}$ Alice Fothergill, Enrique Maestas, and Joanne Darlington. "Race, Ethnicity and Disasters in the United States: A Review of the Literature." Disasters 23 (1999): 156-173.
} 
Issues of racism paint a vivid picture of increased vulnerability and risk to disasters for communities of color across the United States. For example, while in many ways class cannot be separated from issues of economic resources and power, race explains marginalization in the disaster experience in a way that socioeconomic factors cannot. ${ }^{39}$ While additional research is needed, suspicions that greater damage stems from disinvestment in the community-poorer upkeep, a lack of infrastructure, and regular maintenance, etc. - are warranted. $5,6,38,40$

Historical and formal planning processes related to racism and classism, in terms of redlining and other forms of racial residential segregation, provide essential context for how these circumstances are systematically created in cities and across communities. EJ research and social vulnerability studies provide the theoretical and methodological tools to critically examine infrastructure outcomes and environmental risks, and formal planning literature specifically offers the policies (e.g.) that set the stage for race-based targeted disinvestment and infrastructure inequalities. These policies and practices early-on were aimed at indigenous people during colonization and Blacks during and following reconstruction and the great migration and every other community of color thereafter. ${ }^{41}$

\section{PLANNING POLICIES AND DEVELOPMENT PATTERNS LINKING EJ AND SV TO INFRASTRUCTURE MANAGEMENT}

Across geographies, infrastructure is managed and improved with support and direct provision from national, state, county, and local municipal governments. The scale and institution responsible for direct provision depend on the system and whether or not the infrastructure network is a matter of national defense or crosses political or jurisdictional boundaries, some even requiring special autonomous districts. There are examples of infrastructure types where the federal government takes on the majority of responsibility such as coastal levees and dams or where states do the same with highways and bridges. Drinking water, stormwater, sewerage, and energy are overwhelmingly the responsibility of local municipal governments and at the very least a local public-private partnership.

Local governments almost always play some part in the planning funding, managing, and maintaining of infrastructure systems. At the end of the day, systems of any kind have to be grounded in local conditions because every other form of planning, from land use to housing, happens at this level of government.

\footnotetext{
${ }^{39}$ Dennis S. Mileti. Disasters by Design: A Reassessment of Natural Hazards in the United States. (Washington, DC: Joseph Henry Press, 1999).

${ }^{40}$ Christopher Burton and Susan L. Cutter. "Levee Failures and Social Vulnerability in the Sacramento-San Joaquin Delta Area, California." Natural Hazards Review 9: (Aug 2008): 136-149.

${ }^{41}$ Danielle Zoe Rivera. "Disaster Colonialism: A Commentary on Disasters beyond Singular Events to Structural Violence." International Journal of Urban and Regional Research (2020). DOI: $10.1111 / 1468-2427.12950$.
}

Discussing planning policies and development patterns provides an opportunity to explore the pathways and geographies at which injustices and vulnerabilities accrue. The EJ literature is clearly focused on the neighborhood level, recognizing the forces that have led people of color to be segregated and isolated onto locally unwanted land uses and in neighborhoods adjacent to environmentally hazardous facilities. Social vulnerability, however, has typically been ascribed to individuals or households. Yet, implicit in this literature is the understanding that these households exist in space and that certain vulnerability characteristics — race/ethnicity and class—are products of social and institutional forces that lead to segregation and concentrated poverty at the neighborhood level.

Yet, much of the social vulnerability literature ignores planning and spatial aspects, or even examines it at too high a level (e.g., the county level) to reveal patterns related to race and class inequalities. Merging these two literatures emphasizes the importance of addressing these vulnerabilities and their associated injustices at the neighborhood, community, and municipal level, where investments in infrastructure are most often made.

There are certain social processes and larger planning and development patterns shaped by racism, classism, power, and privilege that create pockets of disadvantage and prosperity. These same ideologies and forces have led to early racial zoning and segregation and legalized redlining and isolation racial minorities resulting in deflated tax bases, built environments in disrepair, the siting of toxic facilities, and disproportionate disaster impacts. These are the very issues behind the concepts of EJ and social vulnerability discussed above.

The social forces that have led to unequal development in a historical sense include Jim Crow laws, racial zoning, redlining, and laws prohibiting racial intermingling. ${ }^{42}$ Following the outlawing of race-based zoning and redlining, the social and planning forces that perpetuate discrimination include private deed restrictions, covenants, or building ordinances, ${ }^{43,44}$ white-flight and urban sprawl, ${ }^{45}$ street and highway planning that have been used as physical mechanisms to separate neighborhoods, ${ }^{46}$ the clustering of public and affordable

\footnotetext{
${ }^{42}$ Steven Hoelscher. "Making Place, Making Race: Performances of Whiteness in the Jim Crow South." Annals of the Association of American Geographers 93 (2003): 657-686.

${ }^{43}$ Christopher Silver. "The Racial Origins of Zoning in American Cities." In Urban Planning and the African American Community: In the Shadows. (Thousand Oaks, CA: Sage Publications; 1997), 23-42.

${ }^{44}$ Christopher Berry. "Land Use Regulation and Residential Segregation: Does Zoning Matter?" American Law and Economics Review 3 (2001): 251-274.

${ }^{45}$ Renaud Le Goix. "Gated Communities: Sprawl and Social Segregation in Southern California." Housing Studies 20 (2005): 323-343.

${ }^{46}$ Charles E. Connerly. "From Racial Zoning to Community Empowerment the Interstate Highway System and the African American Community in Birmingham, Alabama." Journal of Planning Education and Research 22 (2002): 99-114.
} 
housing, ${ }^{47}$ municipal underbounding, ${ }^{48,49}$ and steering and home buying discrimination. ${ }^{50}$ These planning policies and development patterns are underlying mechanisms that inform uneven urban development and some of them predate contemporary zoning and have persisted as land-use controls in some places to maintain invisible racial zoning and pockets of racial disadvantage.

\section{Neighborhood disinvestment}

Communities of color have been subjected to a set of planning policies and development patterns ultimately setting the stage for targeted disinvestment. ${ }^{51}$ Furthermore, communities of color often find themselves in communities characterized by dilapidated housing stock, stifled growth, and marginal tax bases-drivers for public services, private investment, community and economic development, and capital improvement. ${ }^{5,52,53}$ Disinvestment creates the differences in neighborhood quality for communities of color that is starkly different from more White and affluent areas. ${ }^{54}$ Disinvestment in particular neighborhoods can also have consequences in times of disaster. The social vulnerability literature has alluded to how communities of color might experience greater damage because they live in more structurally vulnerable (i.e., poorer quality) homes in more physically vulnerable (e.g., lower lying) areas. ${ }^{55}$

Within our current economic and political system, investment and disinvestment impact tax bases, which are necessary to support capital improvement, environmental restoration, and the management of critical infrastructure. Yet, too often, planners, engineers, and others engaged in infrastructure management fail to consider the impact of tax bases and investment decisions

\footnotetext{
${ }^{47}$ Douglas S. Massey and Shawn M. Kanaiaupuni. "Public Housing and the Concentration of Poverty." Social Science Quarterly 74 (1993): 109-122.

${ }^{48}$ Ben Marsh, Allan M. Parnell, and Ann Moss Joyner. "Institutionalization of Racial Inequality in Local Political Geographies." Urban Geography 31 (2010): 691-709.

${ }^{49}$ Gregory D. Squires and Charis E. Kubrin. "Privileged Places: Race, Uneven Development and the Geography of Opportunity in Urban America." Urban Studies 42 (2005): 47-68.

${ }^{50}$ Shannon Van Zandt. "Racial/Ethnic Differences in Housing Outcomes for First-Time, Low-Income Home Buyers: Findings from a National Homeownership Education Program." Housing Policy Debate 18 (2007): 431-474.

${ }^{51}$ Marc Seitles. "The Perpetuation of Residential Racial Segregation in America: Historical Discrimination, Modern Forms of Exclusion, and Inclusionary Remedies." Journal of Land Use \& Environmental Law 14 (1998): 89-124.

${ }_{53}^{52}$ Christopher Silver (1997). Op. Cit.

${ }^{53}$ Douglas Massey and Nancy Denton. American Apartheid: Segregation and the Making of the Underclass. (Cambridge, MA: Harvard University Press, 1993).

${ }^{54}$ Myron Orfield. "Land Use and Housing Policies to Reduce Concentrated Poverty and Racial Segregation." Fordham Urb LJ 33 (2005): 877.

${ }^{55}$ Shannon Van Zandt. "Impacts on Socially Vulnerable Populations." In The Routledge Handbook of Urban Disaster Resilience: Integrating Mitigation, Preparedness, and Recovery Planning. Michael Lindell (ed). (New York: Routledge, 2019), $33-51$.
}

on communities and how social and infrastructural processes and outcomes are inextricably linked. Contemporarily, among several other crises, we are in the midst of an infrastructure crisis where systems are past their prime and decaying infrastructure is omnipresent.

Within any crisis, per the social vulnerability literature, social stratification is inherent, yet no attention has been paid to where and on whom the burdens of decaying infrastructure fall heaviest and the risks associated with infrastructure failure. It is the responsibility of planners and local government to address disparities in infrastructure and impartially ensure basic services and public safety. EJ and social vulnerability theory begs the question of environmental protection and disparate disaster risks, while the land-use planning and housing literature illuminate the pathways for targeted disinvestment and infrastructure disparities. Still, there is little to no research that clearly connects these paradigms.

Literature that explicitly links infrastructure provision with differential environmental and climate-related hazard exposures is especially scant, even though anecdotally we know that infrastructure and critical facilities can modify vulnerabilities and accompany risks. The conceptual framework to follow provides a new way to explore these relationships.

\section{CRITICAL INFRASTRUCTURE: THE NEXT FRONTIER FOR SOCIAL VULNERABILITY AND EJ}

Design and management processes for critical infrastructure are vital to understanding environmental injustices and social vulnerabilities through the receipt of basic services and environmental protections at the neighborhood level. ${ }^{56,57}$ Disparities in provision and unequal protection can impact everyday mitigation and disaster resistance. ${ }^{58}$ Therefore, future applications of the present theories of EJ and SV, including modeling risks of hazard exposure and damage in the aftermath of disasters, must include variables that account and control for the management (i.e., inventory, distribution, and condition) of critical infrastructures.

\section{The role of critical infrastructure}

Critical infrastructures consist of man-made systems that function to produce and distribute a continuous flow of essential services toward basic comfort, safety, and protection. ${ }^{59}$ Infrastructure can include a variety of

\footnotetext{
${ }^{56}$ Jay M. Stein. Public Infrastructure Planning and Management. (Thousand Oaks, CA: Sage Publications, 1988).

${ }^{57}$ Andrew C. Lemer. "We Cannot Afford Not to Have a National Infrastructure Policy." Journal of the American Planning Association 58 (1992): 362-367.

${ }^{58}$ Melanie Kappes, Maria Papathoma-Köhle, and Margreth Keiler. "Assessing Physical Vulnerability for Multi-Hazards Using an Indicator-Based Methodology." Applied Geography 32 (2012): 577-590.

${ }^{59}$ Steven M. Rinaldi, James P. Peerenboom, and Terrence K. Kelly. "Identifying, Understanding, and Analyzing Critical Infrastructure Interdependencies." IEEE Control Systems 21 (2001): 11-25.
} 
structural assets, for example, those physical systems and facilities that are sometimes called public works and are developed or acquired by public agencies to house governmental functions and provide water, power, waste disposal, transportation, and similar services to facilitate the achievement of common social and economic objectives. ${ }^{60}$ A more inclusive definition of infrastructure refers to all these combined facilities that provide essential services of transportation, utilities (water, gas, electric), energy, telecommunications, waste disposal, park lands and green space, recreation, and on occasion housing. ${ }^{53,61}$ Infrastructure also involve socio-physical systems used to provide services to the public through medicine and first response, such as public health and emergency services. ${ }^{62,63}$

\section{Infrastructure, the environment, and disaster}

SV illuminates the insidious ways in which some groups are disadvantaged in their ability to mitigate, adapt to, respond to, and recover from hazard exposures and disaster damage. This in part is due to a lack of infrastructural integrity explained by the inheritance of older and poorer quality housing by low-income and minority folks that can be further explained through the legacy neighborhood planning forces and ongoing disinvestment. ${ }^{2}$

The complex nature of recent events in Houston, Texas, and the broader Gulf Coast region encourages us to take a step back and reevaluate the context of the devastation. The intersection of global climate change, infrastructure crisis, and local urban development heightens the stakes for people already living at the social, economic, and political margins of society. Disaster scholars have long demonstrated that low-income people and racial minorities are the most likely to live in lowlying areas and in lower quality housing, placing them at continual threat of flooding and other hazards.

A systematic framing of the management of infrastructure (e.g., design, installation, distribution, maintenance and rehabilitation, level-of-service, and in-service operation) that can affect risks, hazard exposures, and resulting disaster outcomes across social groups is needed. Table 1 provides selected mentions of infrastructure from the EJ and SV literature specially related to flooding risks, environmental threats, and natural hazards. This

\footnotetext{
${ }^{60}$ W. Ronald Hudson, Ralph C.G. Haas, and Waheed Uddin. Infrastructure Management: Integrating Design, Construction, Maintenance, Rehabilitation, and Renovation. (New York, NY: McGraw-Hill, 1997).

${ }^{61}$ Neil S. Grigg. Water, Wastewater, and Stormwater Infrastructure Management. (Boca Raton, FL: CRC Press, 2012).

${ }^{62}$ Benjamin J. Ryan, Richard C. Franklin, Frederick M. Burkle, Kerrianne Watt, Peter Aitken, Erin C. Smith, and Peter Leggat. "Defining, Describing, and Categorizing Public Health Infrastructure Priorities for Tropical Cyclone, Flood, Storm, Tornado, and Tsunami-Related Disasters." Disaster Medicine and Public Health Preparedness 10 (2016): 598-610.

${ }^{63}$ Maureen Lichtveld, Hannah Covert, and Mya Sherman. "The Gulf Region Health Outreach Program as a Model for Strengthening the Fragile Public Health Infrastructure." Journal of Public Health Management and Practice 23 (2017): S8-S10.
}

work discusses the potential for infrastructure to support resistance to environmental threats when well planned, managed, and maintained, or in contrast, sustain and exacerbate exposure and damage when infrastructure is in poor condition, inadequately maintained, or has outdated capacities. $^{2}$

Hurricane Katrina demonstrated that the negative effects of inadequately provided and poorly maintained stormwater management systems fall heaviest on the poor and people of color. ${ }^{17}$ The integrity of infrastructure describes the quality of equipment, original construction, and current condition. Infrastructure integrity produces better reliability, improved service, lower risk, greater safety, and improved public health and environmental stewardship, such as protection against flood damages. ${ }^{53}$

Our nation's critical infrastructure is antiquated, outdated, and in disrepair, especially in communities of color. ${ }^{64}$ Bullard challenges the nation to redefine "environment" to include infrastructure problems that threaten the fabric of our cities and their inhabitants. ${ }^{65}$ The repairing or replacing of outdated stormwater systems, absent green space, and decayed sewer lines and upgrading existing and building new pumps and sewer plants qualify as infrastructure and are essential services.

For example, green space, different forms of lowimpact development, and more hybrid solutions that include both gray and green infrastructure are projected to reduce stormwater runoff volumes, decrease peak discharge, treat water pollutant loads, and enhance ecosystem services. ${ }^{66,67}$ In fact, some studies have demonstrated that by working with nature and employing green approaches can lower the percentage of urban damage and mitigate future threats from tidal inundation and coastal flooding. ${ }^{68}$

Other studies have shown how the use of green infrastructure and low-impact development can yield significant stormwater control particularly for small events and when combined with other best management practices provided runoff level controls for more intense

\footnotetext{
${ }^{64}$ American Society of Civil Engineers. America's infrastructure grade. (2017). <https://www.infrastructurereportcard .org/americas-grades $>$. (Last accessed on November 21, 2020).

${ }^{65}$ Robert D. Bullard. "Urban Infrastructure: Social, Environmental, and Health Risks to African Americans." In Handbook of Black American Health: The Mosiac of Conditions, Issues, Policies and Prospects. Ivor Lensworth Livingston (ed). (Westport, CT: Greenwood Publishing, 1994), 313-330.

${ }^{66}$ Manasvini Thiagarajan, Galen Newman, and Shannon Van Zandt. "The Projected Impact of a Neighborhood-Scaled GreenInfrastructure Retrofit." Sustainability 10 (2018): 3665.

${ }^{67}$ Elisabeth M. Hamin, Yaser Abunnasr, Max Roman Dilthey, Pamela K. Judge, Melissa A. Kenney, Paul Kirshen, Thomas C. Sheahan, Don J. DeGroot, Robert L. Ryan, Brain G. McAdoo, Leonard Nurse, Jane A. Buxton, Ariana E. Sutton-Grier, Elizabeth A. Albright, Marielos Arlen Marin, and Rebecca Fricke. "Pathways to Coastal Resiliency: The Adaptive Gradients Framework." Sustainability 10 (2018): 2629.

${ }^{68}$ Melissa Wagner, Joanna Merson, and Elizabeth A. Wentz. "Design with Nature: Key Lessons from McHarg's Intrinsic Suitability in the Wake of Hurricane Sandy." Landscape and Urban Planning 155 (2016): 33-46.
} 
Table 1. Selected Mentions of Infrastructure in the Environmental Justice AND SOCIAL Vulnerability Literatures

\begin{tabular}{|c|c|}
\hline Source & Excerpts \\
\hline \multicolumn{2}{|l|}{ Social vulnerability } \\
\hline Mileti $^{39}$ & $\begin{array}{l}\text { Disaster losses result from the Interactions among three major systems: the physical } \\
\text { environment, which includes environmental hazards; the social world; and the } \\
\text { buildings, roads, bridges, and other components of the constructed environment. }\end{array}$ \\
\hline Cutter et al. ${ }^{80}$ & $\begin{array}{l}\text { Public infrastructure-are influential in amplifying or reducing overall vulnerability } \\
\text { to hazards. }\end{array}$ \\
\hline Cutter et al..$^{9}$ & $\begin{array}{l}\text { The quality of human settlements (housing type and construction, infrastructure, and } \\
\text { lifelines) and the built environment are also important in understanding social } \\
\text { vulnerability, especially as these characteristics influence potential economic } \\
\text { losses, injuries, and fatalities from natural hazards. }\end{array}$ \\
\hline Burton and Cutter ${ }^{40}$ & $\begin{array}{l}\text { Pockets of high vulnerability largely driven by social factors warrant management } \\
\text { concern about the disproportionate impact of catastrophic levee failures on these } \\
\text { populations and the level of local, state, and federal preparedness to cope with } \\
\text { such an event. }\end{array}$ \\
\hline Kappes et al. ${ }^{58}$ & $\begin{array}{l}\text { Infrastructure and agriculture are very important for a community. Disruption of } \\
\text { transport routes and lifelines can make the work of rescue teams very difficult. } \\
\text { Damages on agriculture will have a significant impact on the economy of the area. } \\
\text { For this reason, in a future development of the present methodology, data } \\
\text { regarding the physical vulnerability of infrastructure and agriculture should be } \\
\text { included. }\end{array}$ \\
\hline Highfield et al. ${ }^{5}$ & $\begin{array}{l}\text { It has long been assumed that racial and ethnic minorities experienced greater } \\
\text { damage because they lived in more structurally vulnerable (i.e., poorer quality) } \\
\text { homes in more physically vulnerable (e.g., lower lying) areas. Our findings } \\
\text { indicate an independent effect for minority status and lower incomes. While } \\
\text { additional research is needed, we suspect that greater damage stems from } \\
\text { disinvestment in the community-poorer upkeep, a lack of infrastructure, and } \\
\text { regular maintenance, etc. }\end{array}$ \\
\hline Cutter et al. ${ }^{22}$ & $\begin{array}{l}\text { Integrating climate change action in everyday city and infrastructure operations and } \\
\text { governance (referred to as "mainstreaming") is an important planning and } \\
\text { implementation tool for advancing adaptation in cities. By integrating climate } \\
\text { change considerations into daily operations, these efforts can forestall the need to } \\
\text { develop a new and isolated set of climate change-specific policies or procedures. } \\
\text { This strategy enables cities and other government agencies to take advantage of } \\
\text { existing funding sources and programs and achieve co-benefits in areas such as } \\
\text { sustainability, public health, economic development, disaster preparedness, and } \\
\text { environmental justice. }\end{array}$ \\
\hline
\end{tabular}

\section{Environmental justice Bullard $^{65}$}

Wilson et al. ${ }^{81}$

Porse $^{82}$

Garcia-Cuerva et al. $^{83}$
The nation must redefine "environment" to include infrastructure problems that threaten the fabric of our cities and their inhabitants. An inadequate sewer treatment plant is an environmental and health threat. The repairing or replacing of decayed sewer lines and upgrading existing and building new sewer plants are investments in America.

The failure of municipalities to install up-to-code sewer and water infrastructure (i.e., underground sewage and drinking water pipes of the adequate size and material) can lead to vulnerabilities in the sewer and water systems, increased levels of harmful microbes and chemicals in residential drinking and surface water supplies, elevated exposure risks, increased occurrence of gastrointestinal and other illnesses, reduced neighborhood quality of life, and higher stress levels among poor people of color residents.

Understanding how green and gray infrastructure investments are distributed across urban areas is important for new goals of promoting environmental justice in planning.

Underprivileged communities typically do not receive as many social and environmental services as advantaged communities. This research explores green infrastructure (GI)-based management strategies that are evaluated at the watershed scale to improve hydrological performance by mitigating stormwater runoff volumes and peak flows. 
and frequent rainfall events. ${ }^{69}$ However, green infrastructure innovations are not absent of management challenges themselves, especially in EJ and socially vulnerable communities. ${ }^{70,71,72}$ In fact, green infrastructure may come with a unique set of issues due to the nature of design.

Concerns to implement and manage green stormwater infrastructure include limitations of funds and personnel, stakeholder buy-in, regulatory systems, public concern, and uncertainties about performance. ${ }^{73,74}$ These green infrastructure management reservations are particularly evident for marginalized communities in light of the costs and feasibility to initially install and properly maintain these systems over a life cycle. ${ }^{75}$ There is an opportunity for green infrastructure to support stormwater management, flood mitigation, and other ecosystem services and social benefits including reducing social vulnerability, access to green space, and improved mental health. ${ }^{76}$ Nevertheless, how power, privilege, planning policies, and development patterns affect infrastructure management have to be examined. ${ }^{77}$

Infrastructures are the fundamental building blocks of neighborhoods. In many cases, neighborhoods without basic services are less resilient to environmental hazards and weather-related threats, as seen in underserved New Orleans neighborhoods impacted by Hurricane Katrina. ${ }^{17}$ Wilson et al. (2010) concluded that more work needs to be done in

${ }^{69}$ Chandana Damodaram, Marcio H. Giacomoni, C. Prakash Khedun, Hillary Holmes, Andrea Ryan, William Saour, and Emily M. Zechman. "Simulation of Combined Best Management Practices and Low Impact Development for Sustainable Stormwater Management." JAWRA Journal of the American Water Resources Association 46, (2010): 907-918.

${ }^{70}$ Sjerp De Vries, Arjen E. Buijs, and Robbert P.H. Snep. "Environmental Justice in The Netherlands: Presence and Quality of Greenspace Differ by Socioeconomic Status of Neighbourhoods." Sustainability 12 (2020): 5889.

${ }^{71}$ Isabelle Anguelovski, Clara Irazábal-Zurita, and James J.T. Connolly. "Grabbed Urban Landscapes: Socio-Spatial Tensions in Green Infrastructure Planning in Medellín." International Journal of Urban and Regional Research 43 (2019): 133-156.

${ }^{72}$ Mahbubur Meenar, Jordan P. Howell, and Jason Hachadorian. "Economic, Ecological, and Equity Dimensions of Brownfield Redevelopment Plans for Environmental Justice Communities in the USA." Local Environment 24 (2019): 901-915.

${ }^{73}$ Stacey Swearingen White and Michael R. Boswell. "Stormwater Quality and Local Government Innovation." Journal of the American Planning Association 73 (2007): 185-193.

${ }^{74}$ Vivek Shandas, A. Marissa Matsler, Liliana Caughman, and Ashley Harris. "Towards the Implementation of Green Stormwater Infrastructure: Perspectives from Municipal Managers in the Pacific Northwest." Journal of Environmental Planning and Management 63 (2020): 959-980.

${ }^{75}$ Marccus D. Hendricks, Galen Newman, Siyu Yu, and Jennifer Horney. "Leveling the Landscape: Landscape Performance as a Green Infrastructure Evaluation Tool for Service-Learning Products." Landscape Journal 37 (2018): 19-39.

${ }^{76}$ Sara Meerow. "A Green Infrastructure Spatial Planning Model for Evaluating Ecosystem Service Tradeoffs and Synergies Across Three Coastal Megacities." Environmental Research Letters 14 (2019): 125011.

${ }^{77}$ Fushcia-Ann Hoover and Theodore C. Lim. "Examining Privilege and Power in US Urban Parks and Open Space During the Double Crises of Antiblack Racism and COVID-19." SocioEcological Practice Research 3 (2020): 55-70. future research to include physical parameters (e.g., infrastructure) to improve our understanding of justice and vulnerability so that mitigation, protection and adaptation policies can be better targeted to the most vulnerable, susceptible, and disadvantaged communities and populations. ${ }^{78}$

Similarly, Van Zandt argued that true community resilience to disasters and threats from climate change requires that priority be given to a community's most vulnerable residents in the distribution of both structural (engineered, built) and nonstructural (land use planning, education) hazard mitigation. ${ }^{79}$

\section{CONCLUSIONS}

\section{Hazard risks and exposure: linking critical infrastructure}

The societal distribution of critical infrastructure as a community element can affect daily environmental conditions and vulnerability and thus produce disparate impacts from environmental extremes, such as flooding. In the environmental planning literature, the prominent paradigm for considering such impacts is EJ, which describes how some individuals, groups, and communities receive less protection than others because of their race, ethnicity, national origin, and economic status. ${ }^{14,82,83}$

Moreover, low-income communities and communities of color bear a disproportionate burden of the nation's environmental problems and occupy spaces where built environments fail to support prosperity. In the hazard mitigation and disaster planning literature, the current paradigm for considering disparities is social vulnerability, which describes how social stratification based on race, income, disability, gender, age, nationality, among others, contributes to differential risks and impacts from disasters.

EJ and social vulnerability complement one another in terms of community race, ethnicity, and class, and agree that the built environment manifests social circumstances. For example, Van Zandt et al. (2012) discussed how housing, infrastructure, the built environment, and other physical inequalities set the stage for disparities at every stage of the disaster cycle. ${ }^{6}$ The quality of

\footnotetext{
${ }^{78}$ Sacoby M. Wilson et al. (2010). Op. cit.

${ }^{79}$ Shannon Van Zandt. 2020. "Resilience is Rawlsian.' In Chapter 3 in Engaged Research for Community Resilience to Climate Change. Shannon Van Zandt, Jaimie Hicks Masterson, Galen D. Newman, and Michelle Annettee Meyer (eds). (New York, NY: Routledge, 2020), 27-40.

${ }^{80}$ Susan L. Cutter, Jerry T. Mitchell, and Michael S. Scott. "Revealing the vulnerability of people and places: A case study of Georgetown County, South Carolina." Annals of the association of American Geographers 90 (2000): 713-737.

${ }^{81}$ Sacoby M. Wilson, Christopher D. Heaney, John Cooper, and Omega Wilson. "Built environment issues in unserved and underserved African-American neighborhoods in North Carolina." Environmental Justice 1 (2008): 63-72.

${ }^{82}$ Erik Porse. "Open Data and Stormwater Systems in Los Angeles: Applications for Equitable Green Infrastructure." Local Environment 23 (2018): 505-517.

${ }^{83}$ Laura Garcia-Cuerva, Emily Zechman Berglund, and Louie Rivers III. "An Integrated Approach to Place Green Infrastructure Strategies in Marginalized Communities and Evaluate Stormwater Mitigation.” Journal of Hydrology 559 (2018): 648-660.
} 
Environmental Justice and Social Vulnerability
Neighborhood Factors and Inequalities
Critical Infrastructure and Public Works
Hazard Risks, Exposure,

and Disaster Recovery

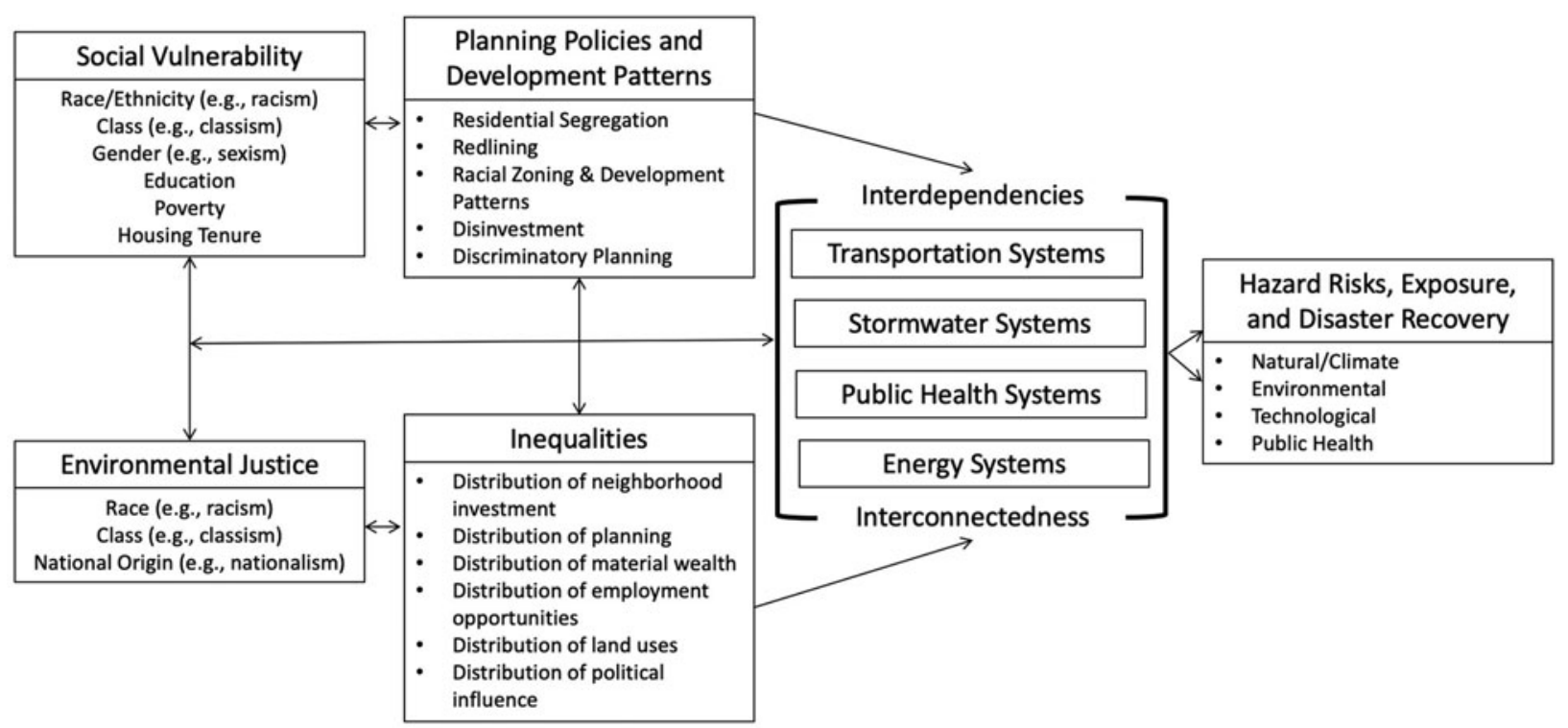

FIG. 1. Environmental justice, social vulnerability, critical infrastructure, and risks framework.

neighborhoods (housing type and construction, infrastructure, and lifelines) and the built environment by way of social circumstances are important in understanding potential economic losses, injuries, and fatalities from environmental hazards. ${ }^{3}$

Social vulnerability is a multifaceted concept that includes dimensions of physical and constructed variables that can help to identify experiences of communities that may or may not support them during environmental hazard exposure. Cutter et al. (p. 258) stated that, "the development and integration of social, built environment, and natural hazard indicators will improve our hazard assessments and justify the selective targeting of communities for mitigation based on good social science, not just political whim.,"9

The literature has shown significant relationships between damage and hazard exposure, physical characteristics, and social characteristics, which corroborate the need to address hazard exposure and the intersection of environmental injustices and social vulnerabilities as part of fundamental infrastructure planning efforts. Figure 1 provides a theoretical framework to guide planning research and practice for critical infrastructure, inequality, and hazard risks.

Infrastructure robustness is a reflection of broader social circumstances in how it's distributed across the hazardscape. Science, practice, and policy has to reframe how infrastructure is explored within particular contexts such as justice, vulnerability to disaster, public health, and climate change. It is also important that we move past discussing social vulnerability as a demographic variable and begin addressing the root causes of vulnerability in terms of racism, classism, sexism, and ableism similar to that of EJ. SV is a function of everyday inequalities that are built into planning policy, practice, and implementation. From hazard exposure to disaster recovery, these disparities will inevitably have consequences for already marginalized groups. Both academics and activists can benefit from this comprehensive understanding of justice and vulnerability achieved through this synthesis of these well-established bodies of literature.

As we as a country grapple with the massive reinvestment needed in our nation's crumbling infrastructure, as well as issues of brutality and climate change, we must intentionally take an anti-environmental racism approach and actively use policy and practice to not allow race vis-àvis racism to drive or determine the distribution of assets and resources, including infrastructure. These structural and nonstructural interventions are a fundamental right to public safety and protection and can support a more resilient and just future for our communities of color.

\section{ACKNOWLEDGMENTS}

This work was in part based on research conducted as a part of the primary author's dissertation completed at Texas A\&M University. That dissertation entitled "The Infrastructures of Equity and Environmental Justice" is a part of an online repository at Texas A\&M University Libraries and is available electronically via the OAKTrust interface here: <http://hdl.handle.net/ 1969.1/161342>.

\section{AUTHOR DISCLOSURE STATEMENT}

The authors certify that they have NO affiliations with or involvement in any organization or entity with any financial interest (such as honoraria; educational grants; participation in speakers' bureaus membership, 
employment, consultancies, stock ownership, or other equity interest; and expert testimony or patent-licensing arrangements) or nonfinancial interest (such as personal or professional relationships, affiliations, knowledge, or beliefs) in the subject matter or materials discussed in this article.

\section{FUNDING INFORMATION}

No funding was received in support of this research.
Address correspondence to: Marccus D. Hendricks Urban Studies and Planning Program School of Architecture, Planning and Preservation University of Maryland 3835 Campus Drive College Park, MD 20742

USA

E-mail: mdh1@umd.edu 